\title{
Sexual harassment reported by undergraduate female physicists
}

\author{
Lauren M. Aycock, ${ }^{1, *}$ Zahra Hazari, ${ }^{2}$ Eric Brewe, ${ }^{2,3}$ Kathryn B. H. Clancy, ${ }^{4,5}$ \\ Theodore Hodapp, ${ }^{6}$ and Renee Michelle Goertzen ${ }^{6}$ \\ ${ }^{1}$ American Association for the Advancement of Science (AAAS) Science \& Technology Policy Fellow, \\ Department of Energy, Washington, District of Columbia, 20585, USA \\ ${ }^{2}$ STEM Transformation Institute, Department of Teaching \& Learning, and Department of Physics, \\ Florida International University, Miami, Florida 33199, USA \\ ${ }^{3}$ Department of Physics and School of Education, Drexel University, \\ Philadelphia, Pennsylvania 19104, USA \\ ${ }^{4}$ Department of Anthropology, University of Illinois at Urbana-Champaign, Urbana, Illinois 61801, USA \\ ${ }^{5}$ Beckman Institute for Advanced Science \& Technology, University of Illinois at Urbana-Champaign, \\ Urbana, Illinois 61801, USA \\ ${ }^{6}$ American Physical Society, College Park, Maryland 20740, USA
}

(Received 17 September 2018; published 22 April 2019)

\begin{abstract}
Sexual harassment occurs more frequently in male-dominated fields and physics is a more maledominated field than most other science, technology, engineering, and mathematics (STEM) fields. Thus, it is important to examine the occurrence and impact of sexual harassment on women in physics. A survey of undergraduate women, who attended a conference for undergraduate women in physics, revealed that approximately three quarters $(74.3 \% ; 338 / 455)$ of survey respondents experienced at least one type of sexual harassment. This sample was recruited from a large fraction of undergraduate women in physics in the United States. We find that certain types of sexual harassment predict a negative sense of belonging and exacerbate the imposter phenomenon. The types of sexual harassment that predict these outcomes, both forms of gender harassment, while seemingly less severe types of harassment, have been found to have substantially negative personal and professional consequences. These findings are important since prior work has found that sense of belonging and the imposter phenomenon are related to students' persistence in STEM fields. Our results have implications for understanding and improving persistence in physics by informing the community about the occurrence of sexual harassment and its effects so that we can begin to work towards reducing its occurrence and mitigating its effects.
\end{abstract}

DOI: 10.1103/PhysRevPhysEducRes.15.010121

\section{INTRODUCTION}

Sexual harassment is a form of gender discrimination. Sexual harassment research has shown that women in maledominated occupations are at greater risk of being sexually harassed [1,2] and that these experiences increase job turnover intentions and withdrawal from work [3,4]. Research across different scientific disciplines is beginning to demonstrate that sexual harassment not only occurs in their fields, but contributes to their educational and professional environments [5,6], further supporting the idea that sexual harassment carries significant career

\footnotetext{
*Corresponding author. lma67@cornell.edu
}

Published by the American Physical Society under the terms of the Creative Commons Attribution 4.0 International license. Further distribution of this work must maintain attribution to the author(s) and the published article's title, journal citation, and DOI. consequences for victims [7]. The field of physics is particularly male dominated, even when compared to other science, engineering, technology, and mathematics (STEM) fields, such as chemistry and biological sciences [8]. Given that a high level of male representation is a known antecedent of sexual harassment in the workplace, how does sexual harassment impact members in a field such as physics? Here, we report on the experiences of sexual harassment of a sample of undergraduate women in physics. We examine the relationship between sexual harassment, particularly gender harassment, and sociopsychological factors that are related to intentions to persist in physics, namely, sense of belonging and the imposter phenomenon.

This paper begins with a discussion of the theoretical framing with respect to sexual harassment, sense of belonging, and the imposter phenomenon. Next, we describe our methods including sample, measures, reliability, and validity. Finally, we present and discuss our results on the experiences of sexual harassment in physics and how 
sexual harassment relates to a discipline-specific sense of belonging and the imposter phenomena.

\section{THEORETICAL BACKGROUND}

\section{A. Sexual harassment}

Sexual harassment is both a legal term and a psychological construct to describe a continuum of behaviors. Legally, sexual harassment is a form of gender discrimination illegal under Title VII of the Civil Rights Act of 1964. Sexual harassment is illegal when it is frequent or severe enough to create a hostile environment or results in an adverse employment decision. Isolated incidents such as infrequent joking or off-hand comments are not illegal [9]. Behaviorally, sexual harassment encompasses three distinct, but related dimensions: sexual coercion, unwanted sexual attention, and gender harassment [10]. Sexual coercion occurs when a job or educational outcome is dependent on a target performing or allowing some sexual act. Unwanted sexual attention includes verbal and nonverbal behaviors directed at a target that are unwanted, offensive, and unreciprocated. Both of these behaviors are generally characterized as "come ons" and are rare [11]. Gender harassment comprises a wide range of behaviors, which convey insulting, hostile, or degrading attitudes about a specific gender or gender representation. These "put downs" are seemingly less severe, and far more common and frequent. Despite the perception that they are less severe, because of their frequency these put downs have similar, and often worse, professional and personal consequences for victims $[4,12]$. These dimensions of sexual harassment are interrelated and overlapping, for example, unwanted sexual attention from a supervisor could also be characterized as sexual coercion [10], and the come on forms of sexual harassment are almost always accompanied by put downs [11].

Research on sexual harassment further separates gender harassment into two categories: sexist and sexual [13]. Both categories of put down convey negative gender-based attitudes, without trying to elicit sexual cooperation. Sexist gender harassment describes experiences which are primarily discriminatory based on one's gender including comments about women's lesser capacity at work, or other derogatory, gender-based comments. For example, when I. I. Rabi said, "Women may go into science, and they will do well enough, but they will never do great science," to Vivian Gornick [14], that is considered sexist gender harassment. In contrast, sexual gender harassment includes behavior which is more explicitly sexual without necessarily being an attempted sexual advance. Posting sexually explicit or objectifying photos of women in an office is an example of sexual gender harassment.

Experiences of sexual harassment have negative psychological, work, and health consequences [2]. These negative outcomes occur even if a woman does not label the experience as sexual harassment [15,16]. Negative job outcomes attributed to sexual harassment includes absenteeism. A survey of 474 astronomers and planetary scientists found that $18 \%$ of women of color and $12 \%$ of white women skipped professional events because they did not feel safe attending them [6]. Skipping a conference for fear of safety limits valuable networking opportunities. This is a tangible impact of sexual harassment on research scientists.

Two important antecedents for sexual harassment are organizational climate and "male domination" $[2,16]$. An organizational climate that communicates a tolerance of sexual harassment is a work environment that meets at least one of the three following criteria: the organization does not take victim's complaints seriously, the organization does not protect victims from retaliation, and/or the organization fails to sanction perpetrators. For example, a study of women employees in different departments and work sites at a utility company found that women experienced higher levels of harassment when they believed that complaints were not taken seriously, it was risky to complain, and/or perpetrators were unlikely to be punished [2]. This has also been validated in the military and for female science faculty $[17,18]$. Male domination is a term for a work environment that meets at least one of the three following criteria: there are more men than women in the work environment, there are more men than women in organizational leadership, and/or it is stereotypically or historically a "male" domain or occupation. Physics is male dominated in all three senses of the definition of male domination: there are more men than women, more men in leadership, and there are strong, negative stereotypes about women in physics that suggest that physics is typically or historically a male discipline [19]. A qualitative analysis of female physics graduate students' experiences has already revealed that a majority of its participants experienced microaggressions-subtle insults or slights - and several reported experiencing more traditional hostile sexism including sexual harassment [20].

\section{B. Sense of belonging}

We define a sense of belonging in an academic discipline as the extent to which a person believes that they are valued, accepted, and legitimate members of the field [21]. Discipline-specific belonging has been shown to relate to discipline-specific persistence. A sense of belonging in math has been shown to predict both men and women's intention to pursue math, and this result remained significant even after controlling for other predictors of persistence in math like domain identification [22]. A longitudinal and daily diary study of women transitioning to college in a STEM major found that women who reported a lower sense of belonging in their STEM major were more likely to expect to switch out of their major [23]. Extensive interviews with women who left STEM majors found that a common reason for their attrition was feeling like an outsider [24]. Factors that effect a sense of belonging for women in STEM include quality and quantity of peers and 
role models, stereotypes about scientists and women, and other outside influences [21]. Sexual harassment, sexist gender harassment in particular, often conveys an individual's belief in stereotypes about gender and gender roles, so we hypothesize that sexual harassment in physics will erode a sense of belonging in physics for female students.

Research on sense of belonging has also focused on specific fields within STEM. For example, women's perceptions of their environment impact their sense of belonging in math. Math environments that convey that math is an innate skill or negative stereotypes about women's ability in math lowered women's sense of belonging in math and thus their desire to pursue math [22]. For women in physics, the educational environment has been shown convey similar trends about the belief that physics is an innate skill and female representation in the field [25]. However, women are more represented in math than in physics. In 2015, only $18 \%$ of students earning a bachelor's degree in physics were women [26]. In 2014, women earned $40 \%$ of the bachelor's degrees in mathematics and statistics, approximately double the percentage of women earning bachelor's degrees in physics [27]. Disciplines where innate brilliance is considered the main criterion for success, as in physics, also tend to have fewer women because of stereotypes that women lack such talent [25]. Thus, it is likely that sense of belonging in physics is a more serious issue for women than in math since more disproportionate male overrepresentation exists along with similar environmental cues conveying that physics is an innate skill and negative stereotypes about women's ability in physics.

\section{The imposter phenomenon}

The imposter phenomenon is an internal experience of believing that one's successes occurred not through genuine ability, but as a result of having been lucky, having worked harder than others, or having manipulated other people's impressions [28]. We are intentionally using the original research terminology to break with the terminology used frequently in the popular press and self-help literature. "Syndrome" implies something is wrong with the individual, rather than the culture. The imposter phenomenon impacts an individual's well being. Many studies find that people who experience imposter phenomenon were less satisfied and lower in self-esteem, had higher anxiety, and were more likely to struggle with the effects of depression than those who did not experience the imposter phenomenon [28-30]. The imposter phenomenon was originally developed to describe internal experiences observed in high achieving women of feeling like a "phony" [28]. Subsequent research has supported that there are no differences in the extent to which men and women generally experience the imposter phenomenon or in some sample populations, men may be more likely to experience the imposter phenomenon [31-33]. Sex differences in experiencing the imposter phenomenon may be sample dependent. Exploring that hypothesis is beyond the scope of this work. Many studies in undergraduate populations recruited from required classes support that women more frequently and to a greater extent experience the imposter phenomenon [30,34].

The imposter phenomenon is hypothesized to impact women's behavior more than men's [31]. Evidence is mounting to support that hypothesis. The imposter phenomenon was a better predictor of achievement-related behaviors in females than in males in a study of undergraduate college students in a variety of majors [34]. A longitudinal study of graduate students in astronomy and astrophysics found that the women surveyed were more likely to experience the imposter phenomenon. The study also linked a higher imposter phenomenon score with an increased likelihood of changing advisors which increased the odds of working outside the field [35]. Additionally, study participants, who were still working in the field and had a higher score on the imposter phenomenon, were more likely to have thought about leaving the field. More work is needed to examine the antecedents and consequences of experiencing the imposter phenomenon, STEM persistence, and student well-being, but current evidence supports that the imposter phenomenon negatively impacts female students in physics.

\section{Research questions}

Given the higher likelihood of harassment in maledominated fields and prior research connecting persistence with sense of belonging and the imposter phenomenon, we wanted to examine the relationship between harassment and sense of belonging as well as harassment and the imposter phenomenon. As such, we address the following research questions drawing on a sample of female undergraduate physicists:

(1) To what extent do female undergraduate physicists experience sexual harassment of different forms?

(2) To what extent does experiencing sexual harassment of different forms correspond with female undergraduate physicists' negative sense of belonging?

(3) To what extent does experiencing sexual harassment of different forms correspond with female physics students' experiencing the imposter phenomenon?

\section{METHODS}

\section{A. Sample}

We recruited survey participants from attendees of the American Physical Society's (APS) Conferences for Undergraduate Women in Physics (CUWiP) in 2017. These conferences are contemporaneous regional conferences held annually. The goals of CUWiP are to increase retention and improve career outcomes of undergraduate women in physics. CUWiP attendees are predominantly female physics majors. There were 1503 CUWiP attendees in 2017 and 1378 CUWiP attendees reported being female 
TABLE I. Confirmatory factor analysis results for harassment constructs $(N=455)$.

\begin{tabular}{|c|c|c|c|c|c|c|}
\hline Latent variable & $\begin{array}{l}\text { Survey item: While in a } \\
\text { context associated with } \\
\text { physics, someone... }\end{array}$ & $\begin{array}{l}\text { Standardized } \\
\text { factor loading } \\
\quad(>0.40)\end{array}$ & SE & $\begin{array}{l}\text { Item } \\
\text { reliability } \\
\left(r^{2}\right)(>0.5)\end{array}$ & $\begin{array}{l}\text { Construct } \\
\text { reliability } \\
(>0.70)\end{array}$ & $\begin{array}{l}\text { Average variance } \\
\text { extracted } \\
(>0.50)\end{array}$ \\
\hline \multirow[t]{2}{*}{$\begin{array}{l}\text { Sexual gender } \\
\text { harassment }\end{array}$} & $\begin{array}{l}\text {...made sexual remarks or told } \\
\text { inappropriate jokes or stories }\end{array}$ & 0.83 & 0.06 & 0.69 & 0.81 & 0.67 \\
\hline & $\begin{array}{l}\text {...made comments of a sexual } \\
\text { nature or tone about your body, } \\
\text { appearance, or clothing or } \\
\text { discussed your sexual activity }\end{array}$ & 0.81 & 0.05 & 0.66 & & \\
\hline \multirow[t]{2}{*}{$\begin{array}{r}\text { Sexist gender } \\
\text { harassment }\end{array}$} & $\begin{array}{l}\text {...made sexist remarks } \\
\text { (e.g., suggesting people of your } \\
\text { sex or gender are not as good at } \\
\text { physics or math) }\end{array}$ & 0.79 & 0.06 & 0.63 & 0.79 & 0.65 \\
\hline & $\begin{array}{l}\text {...treated you differently, ignored } \\
\text { you, or put you down because of } \\
\text { your sex or gender }\end{array}$ & 0.82 & 0.06 & 0.67 & & \\
\hline \multirow[t]{2}{*}{$\begin{array}{l}\text { Unwanted sexual } \\
\text { attention }\end{array}$} & $\begin{array}{l}\text {...repeatedly asked you out, } \\
\text { messaged or contacted you after } \\
\text { you said "no" or asked the } \\
\text { person to stop }\end{array}$ & 0.81 & 0.04 & 0.66 & 0.67 & 0.51 \\
\hline & $\begin{array}{l}\text {...touched you without your } \\
\text { permission making you } \\
\text { uncomfortable }\end{array}$ & 0.61 & 0.03 & 0.37 & & \\
\hline
\end{tabular}

undergraduate students. Our analysis was performed only on the students who identified as female, undergraduate students. The National Science Foundation's National Center for Science and Engineering Statistics (NCSES) reports that 1349 women graduated with a bachelor's degree in physics in 2015 [26], indicating that this survey is able to reach a very large fraction of women in physics. Online pre- and postconference surveys were administered to assess whether the conferences were accomplishing their goals. Participation was voluntary and informed consent was obtained from all survey participants. We obtained Institutional Review Board approval for this project from the University of Maryland, Project No. 505475-11.

The preconference surveys were administered at the time of registration. Postconference surveys were emailed to the CUWiP attendees after the completion of the conference. For the purposes of this study, postconference survey data were utilized since the focal harassment items appeared on this survey (conference organizers did not want to bias attendance by including these questions on the preconference survey). The preconference survey included a gender variable, where the conference attendees self-identified as "female, male, or other". We used the survey responses from all the attendees that identified as female. The wording for the harassment items is shown in Table I. The postconference survey was taken by 471 female undergraduate attendees with 464 responding to at least one harassment item $(<2 \%$ missing). Missing data was listwise deleted for our analysis. The response rate to these items by overall conference attendees was $31 \%$ (similar to postconference survey response rate).
In comparing respondents to our items and overall conference attendees, we did not find substantial differences in demographic data. The respondents were $45.6 \%(215 / 471)$ in their first or second year of college or university and 54.4\% (256/471) in their third or higher year. Similarly, the overall conference attendees were $43.3 \%(596 / 1378)$ in their first or second year and $56.7 \%(782 / 1378)$ in their third or higher year. A majority of the respondents $(76.0 \%, 358 / 471)$ and the overall conference attendees $(72.9 \%, 1005 / 1378)$ are white women. The respondents and overall conference attendees are $21.4 \%(101 / 471)$ and $23.4 \%$ (322/1378) students historically underrepresented in physics, respectively. These percentages are well above the $12.2 \%$ (164/1349) of female students from historically underrepresented groups graduating with physics degrees, indicating an oversampling of historically underrepresented students within physics. Asian women are $16.6 \%(78 / 471)$ of the respondents and $19.2 \%$ of the overall conference attendees. For more details on the demographic data on race and ethnicity for the respondents, overall conference attendees, and the NCES data, see Appendix A. The mean physics GPA for the respondents was 3.49 with a 0.48 standard deviation, and the mean for the nonrespondents was 3.36 with a 0.53 standard deviation. Both physics GPA distributions were skewed towards higher GPAs above the distribution's mean.

\section{B. Predictors}

Drawing on prior theory, we adapted sexual harassment questions from the sexual experiences questionnaire (SEQ), an extensively used, valid, and reliable instrument $[13,36]$. 
TABLE II. Negative sense of belonging items from the preconference survey.

With respect to a physics community, to what extent do you...

$\begin{array}{lllllll}\text { Not at all } & 0 & 1 & 2 & 3 & 4 & \text { Very much so }\end{array}$

...feel different from others in the community

$\begin{array}{llllll}\mathrm{O} & \mathrm{O} & \mathrm{O} & \mathrm{O} & \mathrm{O}\end{array}$

...feel alone or isolated

$\begin{array}{llllll}\mathrm{O} & \mathrm{O} & \mathrm{O} & \mathrm{O} & \mathrm{O}\end{array}$

...feel inadequate as a member

$\begin{array}{lllll}\mathrm{O} & \mathrm{O} & \mathrm{O} & \mathrm{O} & \mathrm{O}\end{array}$

The three types of sexual harassment questions we included were sexual gender harassment, sexist gender harassment, and unwanted sexual attention. We chose these three forms of harassment since they were previously found to be most prevalent-sexual coercion is rare and does not occur in isolation - and due to practical space limitations $[11,13]$. We limited the experiences to the past two years or since the participant began taking physics, whichever is shorter. The preamble to the items is published in full in Appendix B. To clarify "in a context associated with physics," we provided these examples: "in research labs, classrooms, instructional settings, department, or student organization events." We also specified that these actions may have come from other students, high school teachers, instructors, or professors. We did not, however, ask students to explicitly report who perpetrated these actions.

Two items were used for each of the following types of harassment: sexual gender harassment, sexist gender harassment, and unwanted sexual attention. The wording for the items appears in Table I. The items describe behavior ranging from sexist remarks up to sexual assault. For each item, response options included "never", "once", "twice", and "more than twice." For quantitative analysis, these were converted to responses of $0,1,2$, and 3 , respectively. To further establish construct validity, a confirmatory factor analysis (CFA) was run to ensure that the items loaded on the theorized factors expected. The CFA results are summarized in Table I. All items load on the appropriately theorized factor at 0.4 or above. The construct reliability was greater than 0.7 for sexual and sexist gender harassment constructs with unwanted sexual attention slightly below this threshold at 0.67 . The fit indices met threshold values with a goodness-of-fit (GFI) and an adjusted goodness-of-fit (AGFI) of 0.99 and 0.95, respectively (threshold is greater than 0.9), non-normed-fit index (NNFI) of 0.97 (threshold is greater than 0.9), root mean square error of approximation (RMSEA) of 0.07 (less than 0.08 indicates acceptable fit), and standardized root mean square residual (SRMR) of 0.02 (less than 0.08 indicates acceptable fit) $[37,38]$. The $\chi^{2}$ fit statistic was not used due to its dependence on sample size. These results collectively support the construct validity of the measures.

The sexual gender harassment factor is defined as the average of the responses to "...made sexual remarks or told inappropriate jokes or stories?" and "... made comments of a sexual nature or tone about your body, appearance or clothing or discussed your sexual activity?". The sexist gender harassment factor is defined as the average of the responses to "...made sexist remarks (e.g., suggesting people of your sex or gender are not as good at physics or math)?" and “... treated you differently, ignored you, or put you down because of your sex or gender?". The unwanted sexual attention factor is defined as the average of the responses to "...repeatedly asked you out, messaged or contacted you after you said "no" or asked the person to stop?" and "...touched you without your permission making you uncomfortable?”.

\section{Outcomes}

A negative sense of belonging factor was created out of the three items listed in Table II. These items load strongly together in an EFA (factor loadings 0.51, 0.84, 0.64) and have a Cronbach's alpha reliability of 0.70 . Although positively worded sense of belonging items were also included in the survey (which loaded separately from the negative sense of belonging items in a factor analysis), the distribution of a composite built from these items was skewed towards the positive end of the scale (skew value $=-0.48$ ); i.e., students generally reported positive sense of belonging based on the items that were used. However, the composite built on the negative sense of belonging items was much more normally distributed with much less skew in the distribution (skew value $=0.11$ ). Thus, the negative composite showed greater spread and variability in experience in the sample, i.e., better differentiated students' feelings of belongingness. The negative sense of belonging factor is the average of the responses to the three items shown in Table II.

Drawing on imposter phenomenon theory, our items were designed to determine how the participant attributed their successes. Because of practical space limitations, we did not use the full Clance's Imposter Phenomenon scale 
TABLE III. Imposter phenomenon items from the preconference survey.

To what extent do you believe your successes are due to...

\begin{tabular}{lcccccc} 
Not at all & 0 & 1 & 2 & 3 & 4 & Very much so \\
\hline ...your ability & $\mathrm{O}$ & $\mathrm{O}$ & $\mathrm{O}$ & $\mathrm{O}$ & $\mathrm{O}$ & \\
$\ldots$...your hard work & $\mathrm{O}$ & $\mathrm{O}$ & $\mathrm{O}$ & $\mathrm{O}$ & $\mathrm{O}$ & \\
$\ldots$ & $\mathrm{O}$ & $\mathrm{O}$ & $\mathrm{O}$ & $\mathrm{O}$ & $\mathrm{O}$ & \\
$\ldots$...good luck & & & & & \\
$\ldots$..others' perceptions of you & $\mathrm{O}$ & $\mathrm{O}$ & $\mathrm{O}$ & $\mathrm{O}$ & $\mathrm{O}$ & \\
\hline \hline
\end{tabular}

[39]. However, our items were designed based on an item on this scale attributing success to luck, and we extended the instrument to include other attributions of success. These items are shown in Table III. These items were not designed to be combined since imposter phenomenon can be experienced in different ways and not every participant will experience each and every aspect of the imposter phenomenon. Rather, the items were designed to determine the effect on the different aspects of imposter phenomenon (i.e., different attributions of success). An indicator that the participant experiences the imposter phenomenon would be if their attribution of their success due to their ability was low, but one or more of the other items was high.

\section{Additional predictor: Recognition}

As we performed our analysis, we found we needed an additional predictor to account for how unwanted sexual attention was predictive of a participant's belief her success was due to her ability. We hypothesized that participants could be interpreting unwanted sexual attention as a form of recognition by others. Recognition by others is a dimension in the theoretical framework for physics identity that also includes the dimensions of student performance, competence, and interest [40]. Research on physics identity has found the dimensions of physics recognition and physics interest to be the strongest predictors of choosing a physics career in the physics identity theoretical framework [41]. A theoretical review of physics identity, how sexual harassment impacts physics identity, and how physics identity impacts the imposter phenomenon is beyond the scope of this article. We used a previously validated dimension of recognition by others as a predictor to account for our results. Our survey included items to measure scholarly recognition by other physics undergraduates and by physics professors or faculty, shown in Table IV. We combined both items into one factor and included this recognition factor in our model for predicting the outcome of attributing success due to ability. This will be explained further in the following sections.

\section{E. Analysis and controls}

We used multiple linear regression to model the extent to which sexual harassment predicts negative sense of belonging and imposter phenomenon items. We controlled for race or ethnicity, year in school, and physics grade point average (GPA). We controlled for race or ethnicity because prior research on undergraduate women of color in STEM majors found women of color reported a weaker sense of belonging than white women [42]. Only significant race or ethnicity identifications were retained in each model. We also controlled for year in school because sense of belonging and experiencing imposter phenomenon have been shown to be predictive of persistence as discussed in the theory section, so year in school may confound that effect. However, we found year in school was not a significant control for any of our outcomes and was removed from the analysis. We controlled for physics GPA to account for our outcome variables not being predicted by prior physics academic achievement (e.g., feelings that successes are because of one's own ability may be related to achievement). After fitting a model with all of our predictors and controls, we performed a backwards elimination of the variables by removing the least significant variables one at a time. We stopped removing variables when all remaining variables were significant with a threshold of $p<0.05$. We performed backwards elimination to understand the strength of the effect, level of significance, and not artificially inflate the $R^{2}$ values. Because our results for the different sexual harassment factors were overlapped, we checked the variance inflation factor (VIF) for each of our models both before and after we performed backwards elimination. The VIF for our models with all three sexual harassment factors were under 2 , so there are no issues with multicollinearity for our separate sexual harassment factors.

TABLE IV. Items to measure recognition from others from the postconference survey.

If applicable, to what extent do you believe the following people... see you as an exemplary physics student?

Not at all $\quad \begin{array}{lllllll}0 & 1 & 2 & 3 & 4 & \text { Very much so }\end{array}$

...other physics undergraduates

$\begin{array}{lllll}\mathrm{O} & \mathrm{O} & \mathrm{O} & \mathrm{O} & \mathrm{O}\end{array}$

...your physics professors/faculty

$\begin{array}{llllll}\mathrm{O} & \mathrm{O} & \mathrm{O} & \mathrm{O} & \mathrm{O}\end{array}$ 


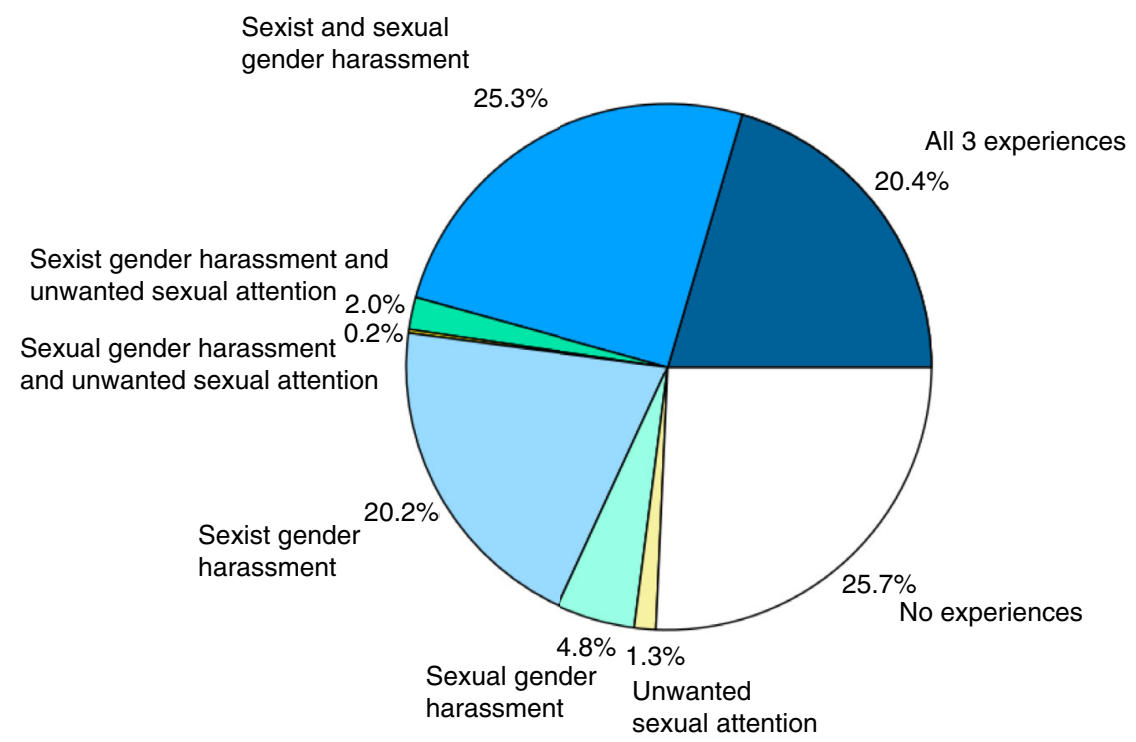

FIG. 1. Combined percentages of types of gender harassment (sexist, sexual) and unwanted sexual attention (USA) reported having experienced in physics by our sample of undergraduate women, with nearly three-quarters $(74.3 \%$; 338/455) of all women responding indicating at least one form of harassment.

\section{RESULTS}

\section{A. Occurrence of sexual harassment}

Overall, 68\% (311/457) of respondents experienced sexist gender harassment, 51\% (236/463) experienced sexual gender harassment, and 24\% (112/463) experienced unwanted sexual attention. Figure 1 displays percentages of participants who experienced each type of sexual harassment in physics as well as combinations of types. We used this method of reporting combined percentages to provide a more comprehensive picture of the respondents' experiences [13]. For example, if a participant reports both experiencing someone making sexist remarks and someone repeatedly asking her out, she would be assigned to a combined category of experiencing sexist gender harassment and unwanted

TABLE V. Regression models predicting students' negative sense of belonging with significant controls included. Note that $* * *: p<0.001, * *: p<0.01, *: p<0.05$.

\begin{tabular}{lcccc}
\hline \hline & \multicolumn{4}{c}{ Negative sense of belonging } \\
\cline { 2 - 5 } & \multicolumn{4}{c}{ Model $(N=420)$} \\
\cline { 2 - 5 } Predictors & $B$ & SE $B$ & $\beta$ & Sig. \\
\hline Intercept & 2.61 & 0.32 & $\ldots$ & $* * *$ \\
Controls & 0.26 & 0.12 & 0.10 & $*$ \\
Asian & -0.23 & 0.09 & -0.12 & $*$ \\
GPA & $\ldots$ & $\ldots$ & $\ldots$ & $\ldots$ \\
Sexual gender harassment & $\ldots .15$ & 0.04 & 0.19 & $* * *$ \\
Sexist gender harassment & $\ldots$ & $\ldots$ & $\ldots$ & $\ldots$ \\
Unwanted sexual attention & $\ldots$ & & & \\
Adjusted $\mathbf{R}^{2}$ & 0.05 & &
\end{tabular}

sexual attention. Figure 1 represents the reported experiences of the 455 participants who responded to all six sexual harassment items.

\section{B. Effect on sense of belonging and imposter phenomenon}

Table $\mathrm{V}$ shows the results of a multiple linear regression model predicting negative sense of belonging. Sexist gender harassment, the most frequently reported experience on our survey, was a significant predictor $(\beta=0.19$; $p<0.001$ ) of a negative sense of belonging in this model.

Table VI shows the results of two multiple linear regression model for participants attributing their successes to good luck and to others' perceptions. Sexual gender harassment, the second most frequent reported experience on our survey, was a significant predictor $(\beta=0.15 ; p<0.01)$ of attributing successes to good luck. Sexual gender harassment was also a significant predictor $(\beta=0.17 ; p<0.001)$ of attributing successes to others' perceptions.

Table VII shows the results of two multiple linear regression models for participants attributing their successes due ability. For the first model, sexist gender harassment was a significant predictor $(\beta=-0.22$; $p<0.001$ ) of attributing successes to ability. Unwanted sexual attention was a significant predictor $(\beta=0.18$; $p<0.001)$ of attributing successes to good luck in this model. For the second model, we included an additional predictor, recognition from other physics undergraduates and physics professors or faculty, and the interaction between recognition and unwanted sexual attention. Although we used the same backward elimination method for this model, we continued to include the control 
TABLE VI. Regression models predicting imposter phenomenon items (successes due to good luck, successes due to others' perceptions) with significant controls included. Note that $* * *: p<0.001, * *: p<0.01, *: p<0.05$.

\begin{tabular}{|c|c|c|c|c|c|c|c|c|}
\hline \multirow[b]{3}{*}{ Predictors } & \multirow{2}{*}{\multicolumn{4}{|c|}{$\begin{array}{c}\begin{array}{c}\text { Successes due to } \\
\text { good luck }\end{array} \\
\text { Model }(N=461)\end{array}$}} & \multirow{2}{*}{\multicolumn{4}{|c|}{$\begin{array}{l}\begin{array}{c}\text { Successes due to } \\
\text { others' perceptions }\end{array} \\
\text { Model }(N=461)\end{array}$}} \\
\hline & & & & & & & & \\
\hline & $B$ & SE $B$ & $\beta$ & Sig. & $B$ & SE $B$ & $\beta$ & Sig. \\
\hline Intercept & 1.65 & 0.08 & $\ldots$ & $* * *$ & 2.21 & 0.12 & $\ldots$ & $* * *$ \\
\hline \multicolumn{9}{|l|}{ Controls } \\
\hline Asian & 0.44 & 0.15 & 0.14 & $* *$ & $\ldots$ & $\ldots$ & & $\ldots$ \\
\hline White & $\ldots$ & $\ldots$ & & $\ldots$ & -0.47 & 0.13 & -0.17 & $* * *$ \\
\hline Sexual gender harassment & 0.16 & 0.05 & 0.15 & $* *$ & 0.19 & 0.05 & 0.17 & $* * *$ \\
\hline Sexist gender harassment & $\ldots$ & $\ldots$ & & $\ldots$ & $\ldots$ & $\ldots$ & & $\ldots$ \\
\hline Unwanted sexual attention & $\ldots$ & $\ldots$ & & $\ldots$ & $\ldots$ & $\ldots$ & & $\ldots$ \\
\hline Adjusted $\mathbf{R}^{2}$ & 0.03 & & & & 0.05 & & & \\
\hline
\end{tabular}

TABLE VII. Regression model predicting students' attributing successes to ability with significant controls included (Model 1). Model 2 accounts for recognition from other physics undergraduates and physics professors or faculty. Note that $* * *: p<0.001$, $* *: p<0.01, *: p<0.05$, not significant (NS).

\begin{tabular}{|c|c|c|c|c|c|c|c|c|}
\hline \multirow[b]{3}{*}{ Predictors } & \multicolumn{4}{|c|}{ Successes due to ability } & \multicolumn{4}{|c|}{ Successes due to ability } \\
\hline & \multicolumn{4}{|c|}{ Model $1(N=416)$} & \multicolumn{4}{|c|}{ Model $2(N=413)$} \\
\hline & $B$ & SE $B$ & $\beta$ & Sig. & $B$ & SE $B$ & $\beta$ & Sig. \\
\hline Intercept & 2.05 & 0.29 & $\ldots$ & $* * *$ & 1.80 & 0.30 & $\ldots$ & $* * *$ \\
\hline \multicolumn{9}{|l|}{ Controls } \\
\hline Hispanic or Latina & 0.30 & 0.11 & 0.13 & $* *$ & 0.24 & 0.11 & 0.10 & $*$ \\
\hline GPA & 0.28 & 0.08 & 0.17 & $* * *$ & 0.14 & 0.08 & 0.08 & NS \\
\hline Sexual gender harassment & $\ldots$ & $\ldots$ & & $\ldots$ & $\ldots$ & $\ldots$ & & $\ldots$ \\
\hline Sexist gender harassment & -0.16 & 0.04 & -0.22 & $* * *$ & -0.15 & 0.04 & -0.21 & $* * *$ \\
\hline Unwanted sexual attention & 0.22 & 0.06 & 0.18 & $* * *$ & 0.18 & 0.18 & 0.15 & NS \\
\hline Recognition from others & & & & & 0.27 & 0.06 & 0.26 & $* * *$ \\
\hline Interaction: Recognition*unwanted sexual attention & & & & & 0.001 & 0.06 & 0.003 & NS \\
\hline Adjusted $\mathbf{R}^{2}$ & 0.07 & & & & 0.13 & & & \\
\hline
\end{tabular}

and predictor variables that were significant in the first model (even if they were not significant in the second) so the two models could be compared. In the second model with recognition included, unwanted sexual attention was not a significant predictor of attributing success due to ability. Sexist gender harassment $(\beta=-0.21 ; p<0.001)$ and recognition from others $(\beta=0.26 ; p<0.001)$ were significant predictors of attributing success due to ability.

Finally, for the last imposter phenomenon item of attributing successes to hard work, there were no significant sexual harassment predictors.

\section{DISCUSSION}

Sexist gender harassment erodes a sense of belonging in physics and attributions of success to students' own ability for our sample of undergraduate female physics majors, yet this and other forms of harassment are often dismissed. Research on discipline-specific sense of belonging has found a sense of belonging in a discipline is directly predictive of persistence in a discipline [21]. Reference [21] provides an extensive review of why sense of belonging is important for women in physics, with suggestions on interventions and recommendations for physics educators. Sexual gender harassment, like remarks and inappropriate jokes or stories, increase attributions of success to external factors like luck and others' perceptions. Thus, as students attribute their success less to their ability and more to external factors like luck and other's perceptions, their imposter phenomenon is exacerbated. This is important since imposter phenomenon has been found to be linked to variables that directly impact persistence [35].

Our results agree well with growing consensus on sexual harassment research that gender harassment, given its frequency and that it is the most common type of sexual harassment, cannot be dismissed and often has the same or worse negative professional and psychological effects as 
isolated instances of sexual coercion [36]. We found that sexual harassment eroded a sense of belonging and exacerbated the imposter phenomenon, which are linked to persistence.

The National Academies of Sciences, Engineering, and Medicine report on sexual harassment of women in the sciences reviewed thirty years of literature that demonstrated that the more women are sexually harassed in an environment, the more they contemplate leaving, and ultimately leave as a result of the sexual harassment [36]. The consequence for academic STEM and physics, in particular, is an additional loss of talent when there are already few women. This is especially true if this level of harassment is already happening at the undergraduate level.

\section{A. Sexual harassment}

Approximately three-quarters $(74.3 \% ; 338 / 455)$ of our survey participants experienced some type of gender harassment or unwanted sexual attention in physics in the last two years. A meta-analysis of sexual harassment research found that academia had an incidence rate of $58 \%$, second to only the military with an incidence rate of $69 \%$ [43]. In our sample, about a quarter $(25.7 \%$; $N=117 / 455)$ of respondents reported no experiences of sexual harassment in physics, similar to the $24 \%$ military women reporting no experiences of sexual harassment in the military in 1995 [13] but less than the $37.4 \%$ female faculty and staff at a large midwestern university reporting no experiences [11]. This is despite the fact that our survey was less extensive than the 24 item SEQ used to measure experiences of sexual harassment in the military and the 18 item SEQ used to measure experience of sexual harassment by female faculty and staff at a university. Additionally, our items did not include sexual coercion. Samples from women in the military and at the university did not show sexual coercion happening in isolation, so the lack of sexual coercion in our survey was unlikely to affect the proportion of participants who did not report being sexually harassed. While it may not be surprising that physics has a higher incidence rate of harassment than an average across academia given the degree of male domination of the field, this result should be considered thoughtfully by the physics community as we work to increase gender equity and change our field's climate.

Our sample consisted of mostly undergraduate women physics majors. Their rank and gender may have made them more vulnerable to sexual harassment, a conclusion consistent with a survey of field work in the sciences that found $76 \%$ of female survey participants reported sexual or inappropriate comments, while $84 \%$ of the women reporting harassment were trainees-a student or a post doc-at the time of the experience [5]. In physics, the APS Ad-Hoc
Committee on Lesbian, Gay, Bisexual, Transgender (LGBT) Issues recently released a report on a climate survey of the members of the LGBT community in physics [44]. In this report, LGBT women experienced exclusionary behavior-defined as behavior that shuns, ignores, or harasses a person-at a significantly greater rate than male participants. The rate was even higher for gendernonconforming physicists. In astronomy and planetary science, harassment experiences varied by gender and race, with women of color experiencing the most hostile environment [6].

\section{B. Negative sense of belonging}

We found sexist gender harassment had a significant effect $(p<0.001)$ on increasing participants' negative sense of belonging. This result is striking because we surveyed a sample of women who we would expect to have a high sense of discipline-specific belonging: our sample was predominantly female physics majors, so almost all intended to complete a physics degree. This result is supported by similar findings for women's sense of belonging in math, where math environments that were perceived by them to convey negative stereotypes about women's ability to do math lowered their sense of belonging [22]. While our effect sizes were moderate, research on women in science has often reported models with similar size effects, significance, and $R^{2}$ [18].

Sexist gender harassment was the most frequent type of sexual harassment we measured on our survey. Among participants, 68\% (311/457) reported experiencing sexist gender harassment either in isolation or in combination with other types of sexual harassment in a physics context. This frequent, often dismissed as not "real" sexual harassment in physics erodes discipline-specific sense of belonging, a trait strongly tied to persistence. This supports the broader finding in the sexual harassment science literature that these seemingly "lesser" forms of harassment have outsized consequences for victims [36,47-49].

\section{Imposter phenomenon}

We found both sexist and sexual gender harassment had a significant effect ( $p<0.01$ and $p<0.001$, respectively) on exacerbating the imposter phenomenon. Sexist gender harassment was found to predict a decrease in participants' attributing their success to their ability even when including the items on recognition by faculty and peers. As mentioned above, the highest percentage of women report experiencing sexist gender harassment. Sexual gender harassment predicted an increase in participants attributing their successes to luck or others' perceptions of them. Sexual gender harassment is the second most experienced type of harassment reported by our sample $(51 \%$, 236/463). By decreasing belief in success due to ability 
and increasing belief in success to external factors like luck and others' impressions, experiencing sexual harassment can increase the likelihood of experiencing the imposter phenomenon.

Our result in model 1, where we found that unwanted sexual attention was predictive of attributing success due to ability, was surprising and not supported by theory. We hypothesized that recognition by other physics undergraduates and physics faculty could be confounding this variable. In other words, it could be the case that women undergraduates who are more recognized by peers and faculty (perhaps because they are more active or outgoing) are more targeted by perpetrators of unwanted sexual attention. To test this possibility, we accounted for recognition in the model. By adding this additional predictor, the effect for unwanted sexual attention became nonsignificant while recognition was highly significant $(p<0.001)$. Furthermore, the interaction effect between recognition and USA was also not significant revealing that USA has the same effect for recognized and unrecognized students, albeit nonsignificant. However, the negative effect for sexist gender harassment remained significant at the $p<$ 0.001 level. Our model accounting for recognition by others, highlights the vulnerability of undergraduate women in physics. Physics recognition has been shown to be important for persistence in physics with women being less recognized than men [41]. Physics recognition is important for students attributing their success to ability. Clearly more qualitative research is needed to better understand how recognition and unwanted sexual attention effects students in physics.

\section{MOVING FORWARD}

Several factors have been shown to reduce the incidence of sexual harassment and mitigate its negative effects on victims. These include increasing the number of women in the workplace, creating and using mechanisms for swift justice towards perpetrators [45], and having leaders who take these concerns seriously and are effective at their jobs [18]. Hiring or admitting diverse women and gender minorities at the faculty, postdoctoral, graduate student, and undergraduate student levels would create opportunities for social support among and across these underrepresented populations. Physics departments, research groups, and professional societies could also consider creating and publicizing professional codes of conduct that identify and promote positive behaviors that increase collaboration, inclusion, and problem solving. These codes of conduct should be tied to extralegal processes to handle breaches of professional conduct, including gender harassment in particular [46]. Department chairs and principal investigators of collaborations and laboratory groups could work to promote the importance of positive professional conduct and speak directly against sexually harassing behaviors. They need to be willing to move quickly in handling cases by prioritizing the reintegration and needs of the victim, rather than the rehabilitation of the perpetrator, and in some cases considering restorative practices should both parties desire it. Together, these actions can significantly reduce organizational tolerance of harassment and male domination in the workplace, the two strongest antecedents of sexual harassment.

Our findings of the pervasiveness of sexist gender harassment and its significant effect on sense of belonging for female undergraduate physicists should be a wakeup call for all physicists who believe that participation in science should be meritorious. We need to work together to ensure that participation in science is not based on who can survive the gauntlet of sexual harassment and other cultural obstacles, or who, by virtue of their identity, can bypass this gauntlet altogether. If we want to produce the great advancements and impactful work, we need to decide together to create an environment that makes it possible for all capable physicists to join and remain in the field.

\section{ACKNOWLEDGMENTS}

We are grateful to the CUWiP National Organizing Committee. L. M. A. thanks Ian Spielman for his support in this work. We thank Laura McCullough for her careful reading of the manuscript and Deepa Cheri for her doublecheck of part of the analysis. This work was supported in part by the National Science Foundation (NSF) under Grant No. PHY 1346627 and PHY-1622510, by the Department of Energy (DOE) under Grant No. DE-1346627, and by a U.S. Department of Energy (DOE) American Association for the Advancement of Science (AAAS) Fellowship sponsored by DOE and administered by the Oakridge Institute for Science and Education (ORISE) for DOE under Contract No. DE-SC00014664. L. M. A. was supported by an American Physical Society (APS) Congressional Science Fellowship. K. B. H.C. by the Illinois Leadership Center Faculty Fellows Program. The authors declare no conflict of interest. All opinions, findings, and conclusions or recommendations expressed in this paper are the authors' and do not necessarily reflect the policies and views of NSF, DOE, ORAU, ORISE or APS. 


\section{APPENDIX A: SAMPLE DEMOGRAPHIC DATA}

Table VIII shows the detailed demographic data on race and ethnicity for the respondents, overall conference attendees, and the NCES data [26].

TABLE VIII. Racial or ethnic groups of our sample of and total female, undergraduate CUWiP 2017 attendees, and bachelor's degrees in physics earned by women at U. S. institutions in 2015 [26]. ${ }^{\dagger}$ This demographic data was collected with slightly different racial or ethnic groups and restricted an individual to only be identified in one racial or ethnic group.

\begin{tabular}{|c|c|c|c|c|c|c|}
\hline Race or ethnicity & Sample & $\%$ & Attendees & $\%$ & Degrees $^{\dagger}$ & $\%$ \\
\hline Total & 471 & 100 & 1378 & 100 & 1349 & 100 \\
\hline HUR & 101 & 21.4 & 322 & 23.4 & 164 & 12.2 \\
\hline Hispanic or Latina & 72 & 15.3 & 242 & 17.6 & 112 & 8.3 \\
\hline Black & 30 & 6.4 & 80 & 5.8 & 48 & 3.6 \\
\hline NAAN & 8 & 1.7 & 27 & 2.0 & 1 & 0.1 \\
\hline NHPI & 3 & 0.6 & 10 & 0.7 & 3 & 0.2 \\
\hline White & 358 & 76.0 & 1005 & 72.9 & $\ldots$ & $\ldots$ \\
\hline w/o Hispanic or Latina & 309 & 65.6 & 845 & 61.3 & $\ldots$ & ... \\
\hline and w/o multiracial & 290 & 61.6 & 782 & 56.7 & 862 & 63.9 \\
\hline Asian & 78 & 16.6 & 264 & 19.2 & 110 & 8.2 \\
\hline Other & 11 & 2.3 & 37 & 2.7 & 53 & 3.9 \\
\hline Multiracial & 26 & 5.5 & 98 & 7.1 & 47 & 3.5 \\
\hline
\end{tabular}

\section{APPENDIX B: REPORTING INDIVIDUAL ITEMS DATA}

Our survey instrument included a preamble before the sexual harassment items in Table IX. The preamble read, "Which of the following have you experienced in a context associated with physics (e.g., in research labs, classrooms, instructional settings, department or student organization events) in the past two years or since you began taking physics (whichever is shorter)? These actions may have come from other students, high school teachers, instructors or professors." Table IX shows the number of participants that responded to each individual item, the percentages for the individual responses to the items, and the raw data in parenthesis.

TABLE IX. Responses to sexual harassment items in our sample of undergraduate attendees of the Conferences for Undergraduate Women in Physics. Which of the following have you experienced in a context associated with physics (e.g., in research labs, classrooms, instructional settings, department or student organization events) in the past two years or since you began taking physics (whichever is shorter)? These actions may have come from other students, high school teachers, instructors or professors.

While in a context associated with physics,

\begin{tabular}{|c|c|c|c|c|c|}
\hline someone... & $N$ & Never & Once & Twice & More than twice \\
\hline $\begin{array}{l}\text {...made sexual remarks or told inappropriate jokes or } \\
\text { stories? }\end{array}$ & 464 & $51 \%(235)$ & $16 \%(76)$ & $6 \%(29)$ & $27 \%(124)$ \\
\hline $\begin{array}{l}\text {...made comments of a sexual nature or tone about } \\
\text { your body, appearance, or clothing, or discussed } \\
\text { your sexual activity? }\end{array}$ & 463 & $70 \%(323)$ & $13 \%(59)$ & $3 \%(15)$ & $14 \%(66)$ \\
\hline $\begin{array}{l}\text {...made sexist remarks (e.g., suggesting people of } \\
\text { your sex or gender are not as good at physics or } \\
\text { math)? }\end{array}$ & 461 & $42 \%(192)$ & $18 \%(82)$ & $11 \%(53)$ & $29 \%(134)$ \\
\hline $\begin{array}{l}\text {...treated you differently, ignored you, or put you } \\
\text { down because of your sex or gender? }\end{array}$ & 460 & $45 \%(205)$ & $17 \%(78)$ & $9 \%(43)$ & $29 \%(134)$ \\
\hline $\begin{array}{l}\text {...repeatedly asked you out; messaged or contacted } \\
\text { you after you said "no" or asked the person to stop? }\end{array}$ & 464 & $81 \%(375)$ & $10 \%(46)$ & $3 \%(15)$ & $6 \%(28)$ \\
\hline $\begin{array}{l}\text {...touched you without your permission making you } \\
\text { uncomfortable? }\end{array}$ & 463 & $85 \%(395)$ & $7 \%(34)$ & $5 \%(21)$ & $3 \%(13)$ \\
\hline
\end{tabular}


[1] J. L. Berdahl, The sexual harassment of uppity women, J. Appl. Psychol. 92, 425 (2007).

[2] L. F. Fitzgerald, F. Drasgow, C. L. Hulin, M. J. Gelfand, and V. J. Magley, Antecedents and consequences of sexual harassment in organizations: A test of an integrated model, J. Appl. Psychol. 82, 578 (1997).

[3] S. Deery, J. Walsh, and D. Guest, Workplace aggression: The effects of harassment on job burnout and turnover intentions, Work Employ. Soc. 25, 742 (2011).

[4] K. P. Jones, C. I. Peddie, V. L. Gilrane, E. B. King, and A. L. Gray, Not so subtle: A meta-analytic investigation of the correlates of subtle and overt discrimination, J. Management 42, 1588 (2016).

[5] K. B. H. Clancy, R. G. Nelson, J. N. Rutherford, and K. Hinde, Survey of Academic Field Experiences (SAFE): Trainees report harassment and assault, PLoS One 9, e102172 (2014).

[6] K. B. H. Clancy, K. M. N. Lee, E. M. Rodgers, and C. Richey, Double jeopardy in astronomy and planetary science: Women of color face greater risks of gendered and racial harassment, J. Geophys. Res. Planets 122, 1610 (2017).

[7] R. G. Nelson, J. N. Rutherford, K. Hinde, and K. B. H. Clancy, Signaling safety: Characterizing fieldwork experiences and their implications for career trajectories, Am. Anthropol. 119, 710 (2017).

[8] S. Cheryan, S. A. Ziegler, A. Montoya, and L. Jiang, Why are some STEM field more gender balanced than others?, Psychol. Bull. 142, 1 (2016).

[9] U.S. Equal Employment Opportunity Commission website, Date accessed March 26, 2019: https://www .eeoc.gov/laws/types/sexual_harassment.cfm.

[10] L. F. Fitzgerald, M. J. Gelfand, and F. Drasgow, Measuring sexual harassment: Theoretical and psychometric advances, Basic Appl. Soc. Psych. 17, 425 (1995).

[11] K. T. Schneider and L.F. Fitzgerald, Job-related and psychological effects of sexual harassment in the workplace: Empirical evidence from two organizations, J. Appl. Psychol. 82, 401 (1997).

[12] C. R. Willness, P. Steel, and K. Lee, A meta-analysis of the antecedents and consequences of workplace sexual harassment, Pers. Psychol. 60, 127 (2007).

[13] L. F. Fitzgerald, V. J. Magley, F. Drasgow, and C. R. Waldo, Measuring sexual harassment in the military: The sexual experiences questionnaire (SEQ-DoD), Mil. Psychol. 11, 243 (1999).

[14] V. Gornick, Women in Science: Then and Now (The Feminist Press at The City University of New York, New York, NY, 2009), pp. 36-37.

[15] V. J. Magley, C. L. Hulin, L. F. Fitzgerald, and M. DeNardo, Outcomes of self-labeling sexual harassment, J. Appl. Psychol. 84, 390 (1999).

[16] L. J. Munson, A. G. Miner, and C. Hulin, Labeling sexual harassment in the military: An extension and replication, J. Appl. Psychol. 86, 293 (2001).

[17] M. S. Harned, A. J. Ormerod, P. A. Palmieri, L. L. Collinsworth, and M. Reed, Sexual assault and other types of sexual harassment by workplace personnel: A comparison of antecedents and consequences, J. Occup. Health Psychol. 7, 174 (2002).
[18] I. H. Settles, L. M. Cortina, J. Malley, and A. J. Stewart, The climate for women in academic science: The good, the bad, and the changeable, Psychol. Women Q. 30, 47 (2006).

[19] A. J. Gonsalves, Physics and the girly girl-there is a contradiction somewhere: Doctoral students' positioning around discourses of gender and competence in physics, Cult. Stud. Sci. Educ. 9, 503 (2014).

[20] R. S. Barthelemy, M. McCormick, and C. Henderson, Gender discrimination in physics and astronomy: Graduate student experiences of sexism and gender microaggressions, Phys. Rev. Phys. Educ. Res. 12, 020119 (2016).

[21] K. L. Lewis, J. G. Stout, S. J. Pollock, N. D. Finkelstein, and T. A. Ito, Fitting in or opting out: A review of key social-psychological factors influencing a sense of belonging for women in physics, Phys. Rev. Phys. Educ. Res. 12, 020110 (2016).

[22] C. Good, A. Rattan, and C. S. Dweck, Why do women opt out? Sense of belonging and women's representation in mathematics, J. Pers. Soc. Psychol. 102, 700 (2012).

[23] B. London, L. Rosenthal, S. R. Levy, and M. Lobel, The influences of perceived identity compatibility and social support on women in nontraditional fields during the college transition, Basic Appl. Soc. Psych. 33, 304 (2011).

[24] E. Seymour and N. M. Hewitt, Talking about Leaving: Why Undergraduates Leave the Sciences (Westview Press, Boulder, CO, 1997).

[25] S. Leslie, A. Cimpian, M. Meyer, and E. Freeland, Expectations of brilliance underlie gender distributions across academic disciplines, Science 347, 269 (2015).

[26] SOURCE: National Science Foundation, National Center for Science and Engineering Statistics, Survey of Research and Development at Universities and Colleges, 2008, Integrated Science and Engineering Resources Data System (WebCASPAR), 2018, https://webcaspar.nsf.gov (Accessed: 07-Apr-2018).

[27] National Center for Statistics and Educational Statistics Field of degree: Women: Mathematics and statistics, 2018, https://www.nsf.gov/statistics/2017/nsf17310/digest/fodwomen/mathematics-and-statistics.cfm (Accessed: 04Aug-2018).

[28] P. R. Clance and S. A. Imes, The imposter phenomenon in high achieving women: Dynamics and therapeutic intervention, Psychother. Theory Res. Pract. 15, 241 (1978).

[29] C. Cozzarelli and B. Major, Exploring the validity of the imposter phenomenon, J. Soc. Clin. Psychol. 9, 401 (1990).

[30] L. N. McGregor, D. E. Gee, and K. E. Posey, I feel like a fraud and it depresses me: The relation between the imposter phenomenon and depression, Soc. Behav. Personal. Int. J. 36, 43 (2008).

[31] P. R. Clance and M. A. O. Toole, The imposter phenomenon: An internal barrier to empowerment and achievement, Women Ther. 6, 51 (1988); http://paulineroseclance.com/ pdf/ip_internal_barrier_to_empwrmnt_and_achv.pdf.

[32] J. Langford and P. R. Clance, The imposter phenomenon: Recent research findings regarding dynamics, personality and family patterns and their implications for treatment, Psychotherapy 30, 495 (1993). 
[33] J. G. Crouch, M. L. Powel, C. Grant, C. Posner-Cahill, and A. Rose, Impostor phenomenon and psychological type among banking and higher education professionals, J. Psychol. Type 20, 34 (1990); https://www.capt.org/jpt/ pdfFiles/Crouch_J_Vol_20_34_42.pdf.

[34] J.E. King and E. L. Cooley, Achievement orientation and the imposter phenomenon among college students, Contemp. Educ. Psychol. 20, 304 (1995).

[35] R. Ivie, S. White, and R. Y. Chu, Women's and men's career choices in astronomy and astrophysics, Phys. Rev. Phys. Educ. Res. 12, 020109 (2016).

[36] National Academies of Sciences Engineering and Medicine, Sexual Harassment of Women: Climate, Culture, and Consequences in Academic Sciences, Engineering, and Medicine (The National Academies Press, Washington, DC, 2018).

[37] L. Hu and P. M. Bentler, PMGComments: Evaluation model fit, in PMGComments:Structural Equation Modeling: Issues, Concepts, and Applications, edited by R. H. Hoyle (Sage, Newbury Park, CA, 1995), pp. 76-99.

[38] K. Schermelleh-Engel, H. Moosbrugger, and H. Müller, Evaluating the fit of structural equation models: Tests of significance and descriptive goodness-of-fit measures, Methods Psychol. Res. Online 8, 23 (2003).

[39] P. R. Clance, The Imposter Phenomenon: Overcoming the Fear That Haunts Your Success (Peachtree Publishers, LTD., Atlanta, Georgia, 1985).

[40] Z. Hazari, G. Sonnert, P. M. Sadler, M. Shanahan, S. Carolina, and S. Carolina, Connecting high school physics experiences, outcome expectations, physics identity, and physics career choice: A gender study, J. Res. Sci. Teach. 47, 978 (2010).

[41] R. M. Lock, Z. Hazari, and G. Potvin, Physics career intentions: The effect of physics identity, math identity, and gender, AIP Conf. Proc. 1513, 262 (2013).
[42] D. R. Johnson, Sense of Belonging among Women of Color in Science, Technology, Engineering, and Math Majors: Investigating the Contributions of Campus Racial Climate Perceptions and Other College Environments (University of Maryland, College Park, 2007).

[43] R. Ilies, N. Hauserman, S. Schwochau, and J. Stibal, Reported incidence rates of work-related sexual harassment in the United States: Using meta-analysis to explain reported rate disparities, Pers. Psychol. 56, 607 (2003).

[44] T. J. Atherton, R. S. Barthelemy, W. Deconinck, M. L. Falk, S. Garmon, E. Long, M. Plisch, E. H. Simmons, and K. Reeves, LGBT Climate in Physics: Building an Inclusive Community (American Physical Society, College Park, MD, 2016), https://www.aps.org/programs/lgbt/ upload/LGBTClimateinPhysicsReport.pdf.

[45] L. M. Cortina, D. Kabat-Farr, E. A. Leskinen, M. Huerta, and V. J. Magley, Selective incivility as modern discrimination in organizations: Evidence and impact, J. Management 39, 1579 (2013).

[46] N. C. Cantalupo and W. C. Kidder, Mapping the Title IX Iceberg: Sexual Harassment of (Mostly) Students by College Faculty, J. Legal Education 66, 4 (2017); https://jle.aals.org/home/vol66/iss4/8/.

[47] R. D. Langhout, M. E. Bergman, L. M. Cortina, L. F. Fitzgerald, F. Drasgow, and J. H. Williams, Sexual harassment severity: Assessing situational and personal determinants and outcomes, J. Appl. Soc. Psychol. 35, 975 (2005).

[48] E. A. Leskinen, L. M. Cortina, and D. B. Kabat, Gender harassment: Broadening our understanding of sex-based harassment at work, Law Hum. Behav. 35, 25 (2011).

[49] V. E. Sojo, R. E. Wood, and A. E. Genat, Harmful workplace experiences and women's occupational well-being: A meta-analysis, Psychol. Women Q. 40, 10 (2016). 